\title{
Julio Cortázar: de pontes e duplos. Uma alegoria da tradução
}

\author{
Julio Cortázar: bridges and doubles. \\ An allegory of the translation
}

\author{
Cristina Santoro* \\ Universidade Federal da Babia \\ Salvador, Bahia, Brasil
}

Resumo: Em quase toda a obra de Julio Cortázar percebe-se uma particularidade: o duplo. Paris $\mathrm{x}$ Buenos Aires, o rio de La Plata x o rio Sena, as pontes, um lado e outro das margens dos rios e do oceano que separam lugares de vivência do autor e que se tornam as chamadas "dos orillas". O duplo, em Cortázar, adota diversas manifestações - espelhos, reflexos, imagens, visões - e o tema do desdobramento deriva de vivências do autor. O duplo, figura central de nossas reflexões, temática presente nos estudos literários e nas abordagens psicanalíticas rankianas, freudianas e lacanianas, pode ser aplicado ao ato tradutório, na medida em que muitos esperam do texto traduzido a construção de uma imagem apenas especular, esquecendo "o duplo" que todo ser (texto) carrega na sua essência mais profunda: um duplo que precede. Outros, no entanto entendem a tradução como ponte entre línguas e linguagens: de um ser para um outro, de uma margem para a outra, de um texto de partida (o 'original') para o seu texto duplo, o texto traduzido. A analogia 'ser-texto' nos abrirá as portas para esse jogo da amarelinha onde a primeira pedra será jogada a partir do texto de partida, para vivenciar a "angústia" na passagem, mímese, identificação e repulsa diante do outro - o duplo - na tentativa de atingir o Céu: o texto de chegada.

Palavras-Chave: Duplo. Pontes. Texto-Ser. Tradução

\begin{abstract}
In almost all the work of Julio Cortázar one perceives a peculiarity: the double. Paris x Buenos Aires, the La Plata river and the Seine river, the bridges, one side and the other of the banks of the rivers and the ocean that separate places of experience of the author and become the so-called "the banks". The double, in Cortázar, adopts diverse manifestations - mirrors, reflections, images, visions - and the theme of the unfolding derives from the author's experiences. The double, central figure of our reflections, the theme present in the literary studies and the psychoanalytic approaches of the Freudian and Lacanian, Freudian and Psychoanalytic approaches can be applied to the translation act, since many expect from the translated text the construction of a just specular image, forgetting " the double "that every being (text) carries in its deepest essence: a double that precedes. Others, however, understand translation as a bridge between languages and languages: from one being to another, from one margin to the other, from a starting text (the 'original') to its double text, the translated text. The analogy 'being-text' will open the door to this game of hopscotch where the first stone will be played from the starting text, to experience the "anguish" in the passage, mimic, identification and repulsion before the other - in the attempt to reach Heaven: the text of arrival.
\end{abstract}

Keywords: Double. Bridges. Text-Being. Translation

\footnotetext{
Mestre e Doutora em Letras e Tradução, Universidade Federal da Bahia. E-mail: crissan2002@gmail.com.
} 
Julio Cortázar viveu e morreu deliciando-se no prazer do texto convidando os leitores para saltar a ponte sobre o rio em viagens duplas, entre a Terra e o Céu, na tentativa de atingir o kibutz do desejo, o Céu, do outro lado do rio, na outra orilla.

As procuras infatigáveis cortazarianas oferecem um vasto leque de elementos narrativos que se tornam sempre obsessões duplas: confrontos de opostos (terra-céu; céu-Céu; o lado de cá-o lado de lá; dentro-fora; galeria coberta-céu; duas margens das águas; textos a serem traduzidos-textos traduzidos; o eu e o outro); irrupção de ficção na realidade, o desdobramento espaço-temporal; o texto-não texto ilustrado por Rayuela: destruição da literatura no fazer literaturário.

A obra de Cortázar é convite para uma narrativa de descoberta, em movimento e criação de atalhos que se bifurcam e desdobram-se inventando duplos, sem cessar. Atalhos narrativos incansáveis que traçam desenho duplo, ponte entre o narrador e o seu duplo: o leitor.

En el fondo lo que pienso de mi obra es que fue tan hermoso escribirla como hacer el amor con la palabra durante 40 años [...] alguna vez se pudo ser un gran escritor sin sentirse partícipe del destino histórico inmediato del hombre, en este momento no se puede escribir sin esta participación que es responsabilidad y obligación y sólo las obras que la transmiten, aunque sean de pura imaginación [...] contendrán de alguna indecible manera ese temblor, esa presencia que las hace reconocibles y entrañables, que despierta en el lector un sentimiento de contacto y cercanía.[...] (CORTÁZAR, 1992, p. 17)

Cortázar é apelo para as nossas inquietações e reflexões quanto ao duplo, não apenas como justificativa de escolhas narrativas, mas também como fundamento do ato tradutório. No universo da linguagem, o duplo inicia-nos, precede-nos e nos convoca para um percurso onde tudo é tradução.

Em entrevista concedida por Julio Cortázar ao escritor Ernesto González Bermejo, encontramos o seguinte recorte:

EGB: ¿Por dónde empezamos? ¿por el tema del doble? [...]

JC: Sí, hay en mí una especie de obsesión del doble [...] El tema del doble es una de las constantes que se manifiesta en muchos momentos de mi obra, [...] Está en "Una flor amarilla"- donde el personaje se encuentra con un niño que es él mismo en otra etapaun cuento escrito veinte años después de "Lejana",[...]

EGB: Y está también en Rayuela. Quizás los casos más ilustres de dobles en su obra sean los de Oliveira/Traveler y La Maga/Talita. JC: - Es verdad que, hacia el final del libro, Oliveira lo llama doppelgänger a Traveler, siente que hay una especie de repetición.[...] no se olvide que los dobles -no sé si explícitamente en el sistema de Jung pero, en todo caso en las cosmogonías, en las mitologías del mundo- el doble, los personajes dobles, los mellizos ilustres: Rómulo y Remo, Cástor y Pólux, los dioses dobles, son una de las constantes del espíritu humano como proyección del inconsciente convertida en mito, en leyenda. (CORTÁZAR.1994)

Para compreender a questão fundamental do duplo, na obra de Cortázar, impõe-se analisar os estudos existentes sobre os sujeitos análogos e a presença dessas figuras no folclore e na concepção dos mitos. O tópico do duplo remete a épocas antiquíssimas, estando presente em alguns poetas que tentaram revelar o seu sentido. No entanto, podemos entendê-lo, simplesmente, como tradução de: a ameaşa de morte do eu. 
O primeiro texto da tradição ocidental, o Gênesis, informa que, a princípio, o homem era um, e Deus o dividiu em dois. A cisão resultou num enfraquecimento da singularidade e a vida passou a ser uma constante busca pela outra metade perdida. Esta concepção faz-se presente nas religiões tradicionais, com a separação entre alma e corpo. Assim, o homem possuiria uma natureza dupla, estruturada através da união de dois elementos diferentes.

[...] Parece que o homem não se aceita como uma unidade. De alguma maneira, sente que poderia estar simultaneamente projetado em uma outra entidade que conhece ou não, mas que existe. Me pergunto [...] se aquelas fantasias de Platão sobre os sexos não têm a ver, um pouco, com isto. Platão se perguntava porque existem homens e mulheres, e acreditava que, originalmente existia só um: o andrógeno, que logo se dividiu em dois. $\mathrm{O}$ amor seria a nostalgia de todos nós de nos tornarmos andrógenos. Quando buscamos uma mulher, estamos buscando o nosso duplo, queremos completar a figura original. Estes temas reaparecem em múltiplas cosmogonias e mitologias e continuam nos habitando. (CORTÁZAR, 1998).

Esta dualidade, antítese ou cisão remete, em termos do imaginário, ao fenômeno especular inscrito no duplo: espelhos, duplos e reflexos habitam as lendas, as histórias de magia e as tradições populares, articulando um profundo sentimento de insegurança individual, social ou comunitária. Esta temática faz parte dos temas literários com profundas raízes mitológicas. A noção do duplo, da réplica, perturba e inquieta a identidade, porque testemunha a insuficiência do ser. No imaginário cultural no século XIX, segundo as informações sobre os conceitos mitológicos freudianos sobre o real, a ilusão e a arte, percebe-se que o duplo pertence ao lado escuro do mundo da mitologia e do folclore: representa a dualidade em seu aspecto mais perplexo e sinistro.

O duplo é uma temática vastamente utilizada na literatura alemã do século XIX, representando o humano como um ser dividido entre um 'eu' e um 'alter ego'. Considerado arquétipo e imagem, a representação do duplo parece inicialmente clara e acessível, embora logo se mostre indefinível e desconcertante. Um exame mais profundo revela, de maneira dramática, sua natureza fluida e enigmática, que escapa de esquemas meticulosamente organizados do real.

O duplo adota diversas formas e manifestações: espelhos, reflexos, sombras de diversos planos, inaugurando imagens deformadas, aparecendo e fazendo alusão aos caleidoscópios de Narciso. A imagem reflexiva e seus poderes têm uma origem bem antiga, como já foi dito, sendo a arte a encarregada de sublimar esta magia que, desde os primeiros tempos do homem e sob mil formas culturais, permite-lhe assumir sua humanidade com recursos ligados permanentemente às conjunções do imaginário. A primeira iniciativa desta mentalidade mágica é a instauração de um duplo, um sósia, uma imagem-espectro. É um processo anterior à consciência e se reconhece no reflexo ou sombra, projetada no sonho, na alucinação, na representação pintada ou esculpida, fetichizada, totemizada, sublimada nas crenças, cultos e ritos das religiões primitivas.

Sigmund Freud, em seu ensaio dedicado ao estudo do Estranho investiga os sentidos da palavra alemã 'heimlich'. Verifica que, além da sua referência mais habitual de - pertencente à casa, familiar, doméstico, íntimo, não estranho - o 
vocábulo se desdobra de tal forma que chega a atingir, no seu limite, o significado de 'escondido', 'algo oculto e perigoso', habitualmente atribuído ao seu oposto 'unheimlich'. Na língua alemã, portanto, o conhecido leva consigo o seu duplo (o estranho) a partir da própria palavra que o nomeia. (FREUD, 1919, p. 279).

Quanto ao fenômeno específico do duplo, Freud afirma:

[...] Assim, temos personagens que devem ser considerados idênticos porque parecem semelhantes, iguais. Essa relação é acentuada por processos mentais que saltam de um personagem para outro, através do que chamaríamos telepatia, de modo que um possui conhecimento, sentimentos e experiência em comum com o outro. Ou é marcada pelo fato de que o sujeito identifica-se com outra pessoa, de tal forma que fica em dúvida sobre quem é o seu eu $(s e l f)$, ou substitui o seu próprio eu (self) por um estranho. Em outras palavras, há uma duplicação, divisão e intercâmbio do eu $($ self). E, finalmente, há o retorno constante da mesma coisa [...]. (FREUD, 1919, p. 293).

A psicanálise discerne significados, agencia significações, constrói sentidos tentando desconstruir as explicações lógicas baseadas na ética e na religião. Vai ao fundo do espírito humano, captar os mais recônditos arquétipos. Narciso, em todo o seu investimento, é uma forma de auto-observação, maneira que o indivíduo tem de manter sua coesão e sua integridade. Aqui entra o duplo, a atividade fantasmática, o retorno da libido (segundo Freud) sobre a própria pessoa, um mecanismo de reversão, como ideal do ego, modelo a que o indivíduo procura conformar-se ou como ego ideal, identifica objetos prestigiados e grandiosos, na busca de um enriquecimento para o eu, na procura do duplo: expressão perfeita e imperfeita, acabada ou inacabada de um sujeito, espelho para medir o ego.

$\mathrm{Na}$ literatura, o termo Doppelgänger, ou duplo, é inicialmente introduzido no final do século XVIII. Motivo bastante recorrente, na literatura romântica, tem a função de resgatar a mitologia. Um renovado interesse por estas manifestações é preponderante no pensamento desta época, quando a Filosofia e a Arte reconhecem estar diante de uma crise espiritual de dimensões profundas. Os escritores se caracterizam como aqueles que tentam salvar os conceitos tradicionais, os esquemas e valores baseados na relação de sujeito e objeto, traduzendo a problemática de uma época, a partir do ficcional.

A maior parte dos estudos realizados na Europa, do século XX, sobre o duplo privilegia o ângulo psicológico, a começar pela interpretação psicanalítica de Otto Rank ao relacionar os diferentes aspectos do duplo na literatura com o estudo da personalidade dos autores.

O tema do 'duplo' foi abordado de forma muito completa por Otto Rank (1914), que se baseou nas ligações que o 'duplo' tem com reflexos em espelhos, com sombras, com os espíritos guardiões, com a crença na alma e com o medo da morte; mas lança também um raio de luz sobre a surpreendente evolução da idéia. Originalmente, o 'duplo' era uma segurança contra a destruição do ego, uma 'enérgica negação do poder da morte', como afirma Rank; e, provavelmente, a alma 'imortal' foi o primeiro 'duplo' do corpo. Essa invenção do duplicar como defesa contra a extinção tem a sua contraparte na linguagem dos sonhos, que gosta de representar a castração pela duplicação [...] O mesmo desejo levou os antigos egípcios a desenvolverem a arte de fazer imagens do morto em materiais duradouros. Tais idéias, no entanto, brotaram do solo do amor próprio ilimitado, do narcisismo primário que domina a mente da criança 
e do homem primitivo. Entretanto, quando essa etapa está superada, o 'duplo' inverte seu aspecto. Depois de haver sido uma garantia de imortalidade, transforma-se em estranho anunciador da morte. (FREUD, 1919, p. 293-294).

Segundo as palavras de Otto Rank, em $O$ duplo (RANK, 2013), a sombra inseparável do homem tornou-se a primeira objetivação da alma humana, provavelmente bem antes de o homem ter percebido sua imagem refletida na água. Foi através da sombra e do reflexo que o homem viu pela primeira vez a sua forma. Posteriormente, representou a sua alma e esta crença primitiva se tornou a origem da crença na alma, sustentada pelos povos da cultura antiga. E salienta, ainda, que o duplo é a própria personalidade (sombra ou reflexo), assegurando sobrevivência futura.

Otto Rank sustenta que o medo da morte nos inspira a inventar a ideia de um duplo: essa obscura réplica de nós mesmos que, segundo se diz, sobrevive num mundo fantasmagórico, ou outro mundo. Na visão de Rank, duplicar a imagem do eu é trabalho de uma negação narcisista da ideia de extinção pessoal. "Rank basa su interpretación de todo el tema del doble en la teoría freudiana del narcisismo [sic] Según esta concepción, el doble representa elementos de morboso amor por sí mismo, que impiden la formación de una personalidad bien equilibrada."(RANK, 2013, p. 7-8).

A vasta abordagem psicanalítica de Otto Rank focaliza o duplo a partir de diferentes pontos de vista: literário, antropológico, biográfico e, fundamentalmente, psicanalítico, abordado a partir do narcisismo e do duplo. Interessante é salientar que Otto Rank desenvolveu pesquisas psicanalíticas como assistente de Sigmund Freud, porém as visões artísticas e literárias imprimem traços peculiares no desenvolvimento científico-discursivo e psicanalítico rankiano. Portanto, em O duplo (RANK, 2013) observa-se uma notória influência e presença das produções literárias dos românticos alemães. Aliás, a pesquisa rankiana baseia-se neles. Otto Rank salienta a importância das narrações fantásticas de E.T.A. Hoffman (HOFFMAN, 1969) como fonte inspiradora do filme $O$ estudante de Praga (HEINZ EWERWS, 1913) que inicia a saga de produção literária e fílmica, no que se refere à abordagem do duplo nas suas inumeráveis manifestações. Embora o ensaio rankiano se fundamente no filme $O$ estudante de Praga, o autor ilustra a questão do duplo também a partir de vários escritores europeus. Observa-se, portanto que a análise do duplo rankiano é apresentada sob diversas imagens: sombras, visões, reflexos, fantasmas, espelhos, vozes-ecos, duplos corpóreos, isto é, duplicações ou réplicas, instaurando, assim, um ponto de partida que nos permitirá desenvolver as figuras da analogia, do originalcópia, tópicos fundamentais nas nossas reflexões.

O psiquiatra Otto Rank analisou os traços psicanalíticos dos autores, na sua pesquisa baseada na literatura, salientando as características das personalidades dos escritores em questão.

No tenemos el propósito de investigar [...] la vida y la obra de los escritores que aquí nos ocupan. Sólo pretendemos mostrar que una sección transversal de determinada capa de su constitución psíquica podría revelar las coherencias complejas de ciertos rasgos característicos, de los cuales resultan reacciones psíquicas idénticas. El rasgo principal que comparten los escritores que nos interesan resulta bastante evidente: ellos 
[...] eran personalidades decididamente patológicas, que en más de un sentido desbordaban inclusive el límite de la conducta neurótica en otros aspectos permitida al artista. Sufrían - y de manera evidente- de perturbaciones psíquicas o de dolencias neurológicas y mentales, y durante su vida demostraron una notable excentricidad de conducta, ya sea en el uso del alcohol, de narcóticos, o en las relaciones sexuales, con un acento especial, en este último caso, en lo anormal. (RANK, 2013, p. 51-52).

Ao longo do texto $O$ duplo, Rank desenvolve a idéia da literatura como tradução e reflexo da personalidade dos narradores e a ilustra seu ponto de vista, a partir de exemplos das vidas dos autores e das análises de trechos significativos das narrativas. Traz, então, numerosos comentários sobre as extravagâncias de Poe e de Maupassant, e também as particularidades da psique de Hoffman (HOFFMAN, 1969): “[...] sabemos que ele tinha alucinações, delírios de grandeza e ideias compulsivas, e ele gostava de descrever em seus escritos. [...]" (RANK, 2013, p. 5152). Tornam-se notáveis as deduções de Rank quanto ao escritor Jean Paul, que temia enlouquecer, e teve que enfrentar graves traumas psíquicos na sua luta pela expressão criadora.

Un factor central de sus conflictos psicológicos es su relación con su yo. Su biógrafo Schneider señala la importancia de éste para las perturbaciones mentales de Jean Paul, y para sus personajes literarios: "Jean Paul relata, como uno de sus recuerdos más significativos de su infancia, que la intuición 'yo soy yo' le surgió, de niño, como un relámpago; y desde entonces siguió siendo una brillante imagen que se erguía ante él... Durante su estadía en Leipzig, esa potente percepción de su propio yo se le impuso como un espectro aterrador. (RANK, 2013, p. 52).

Rank aborda esses traços psíquicos dos diferentes escritores a partir de uma análise pormenorizada dos seus comportamentos, enfatizando como esses aspectos, tão particulares, definem a produção literária de todos eles. O fato de Rank salientar a aparição ou desdobramento do eu como figura e motor de criação narrativa, torna-se evocativo de várias das características do narrador cortazariano.

Ao abordar a problemática do duplo em Cortázar, o tema do desdobramento do eu pode se ilustrar a partir de uma lembrança-vivência de alucinação (e desdobramento) de Cortázar. A título de esclarecimento vale retomar esse tópico, através de outros parágrafos de entrevistas concedidas por Cortázar, no sentido de exemplificar e confirmar a teoria rankiana.

AB: Para muchos, escribir es un acto de exorcismo. En su caso, ¿algún cuento o novela ha cumplido esa función? JC: Una buena parte de mis cuentos han nacido de estados neuróticos, obsesiones, fobias, pesadillas. Nunca se me ocurrió ir al psicoanalista; mis tormentas personales las fui resolviendo a mi manera, es decir, con mi máquina de escribir y ese sentido del humor que me reprochan las personas serias. Entonces, más que un cuento o una novela, es el escribir mismo mi acto de exorcismo. [...] Vivo como habitado por lo imaginario, que se superpone a lo que me rodea, lo modifica y lo desplaza. Es un sentimiento a la vez maravilloso e inquietante, un periodo en el que se acumulan las coincidencias, y los encuentros, como si el libro y la realidad exterior se invadieran mutuamente hasta el día -siempre triste para mí- del punto final. (BERNECHEA, 2012). 
Numa outra entrevista concedida ao escritor uruguaio Omar Prego, a conversa aborda o conto Axolot $l^{1}$ focalizando a temática dos traços obsessivos da personalidade de Cortázar, como fonte de inspiração literária:

[...] Eso es una experiencia de la vida cotidiana. Yo fui al Jardin des Plantes y lo visité -a mí me gustan los zoológicos- y de golpe, en una sala como la que se describe en el cuento, muy vacía y muy penumbrosa, vi el acuario de los axolotl y me fascinaron. Y los empecé a mirar. Me quedé media hora mirándolos, porque eran tan extraños que al principio me parecían muertos, apenas se movían [...] Sé que en un momento dado, en esa intensidad con que yo los observaba, fue el pánico. Es decir, darme vuelta e irme, pero inmediatamente, sin perder un segundo. Cosa que, naturalmente, no sucede en el cuento. En el cuento el hombre está cada vez más fascinado y vuelve y vuelve hasta que se da vuelta la cosa y se mete en el acuario [...] Pero mi huida, ese día, fue porque en ese momento sentí como el peligro [...] Y entonces huir. Yo huí. Y esto es absolutamente cierto; será un poco ridículo pero es completamente cierto: jamás he vuelto al acuario del Jardin des Plantes, jamás me voy a acercar a ese acuario. (CORTÁZAR, 1982).

A escrita como catarse, exorcismo, pulsão, massa narrativa em constante luta: contra e para outro. Duplos em briga mortal, ou em metamorfose infatigável, criando tensão discursiva, justificativa para uma literatura fantástica que se filtra no cotidiano.

No que diz respeito à vasta produção dos diferentes autores analisados, Rank encontra explicação da ânsia e da necessidade ficcional, salientando a presença do duplo, ao focalizar. "La disposición patológica hacia las perturbaciones psicológicas está condicionada en gran medida por la división de la personalidad." (RANK, 2013, p. 68). Observa-se, portanto que o elemento do duplo é figura constante.

Son las extrañas representaciones del doble como espejo, como sombra, imagen de espejo o retrato, cuya evaluación significativa no entendemos del todo, aunque podamos seguirla en términos emocionales. En el escritor, lo mismo que en su lector, aquí parece vibrar en forma inconsciente un factor sobre individual, que otorga a estos motivos una misteriosa resonancia psíquica. (RANK, 2013, p. 69).

A escrita cortazariana acarreta presença e rechaço das criaturas invasoras na construção narrativa: pavor e fascínio do duplo - criaturas invasoras - exorcismo e repulsa, visando paradoxalmente a existência universal, ao mesmo tempo em que as situa no outro extremo da ponte (CORTÁZAR, 1974, p. 230). Julio Cortázar vai se filtrando nas nossas inquietações, nos propondo os seus parâmetros criativos numa tentativa de compreensão da gênese fantástico-narrativa, olhando para as duas margens, temática de base destas reflexões.

Cortázar explica-se e nos esclarece a questão rankiana a partir da sua ótica de contista do fantástico, salientando o ato de criação literária como uma fase de produção, na magia da escrita.

[...] certa gama de contos nasce de um estado de transe, anormal para os cânones da anormalidade corrente, e que o autor os escreve enquanto está no que os franceses

\footnotetext{
1 "Axolotl", da coletânea Bestiario -1951-, é um conto fantástico-existencial de Julio Cortázar. Trata-se da história de um homem que visita o Jardin des Plantes de Paris e entra numa espécie de transe de identificação com os Axolotl que habitam o fundo do aquário, até se tornar Axolotl e o bichinho homem.
} 
chamam um état second. [...] Não faltará quem julgue que exagero esta noção de um estado ex-orbitado como o único terreno onde possa nascer um conto breve, [...] me refiro a narrativas onde o próprio tema contém a 'anormalidade', como os [...] de Poe [...] Como descrever a atmosfera que antecede e envolve o ato de escrevê-lo? [...] sem aviso prévio [...] é um conto, uma massa disforme, sem palavras, nem rostos, nem princípio, nem fim, mas já um conto [...] há uma espécie de um grande coágulo [...] há $a$ angústia e a ansiedade e a maravilha, porque também as sensações e os sentimentos se contradizem nesses momentos, escrever um conto assim é simultaneamente terrivel e maravilhoso [...] E então a massa negra se aclara [...] o que provocou a obsessão, o coágulo abominável que era preciso arrancar em tiras de palavras. [...] (CORTÁZAR, 1974, p. 230)

Cortázar escreve criando pontes entre o narrador e o narrado, entre o narrador e o leitor, já que para ele existe uma ponte que os precede: a ponte de uma linguagem "indo de uma vontade de expressão à própria expressão. Ao mesmo tempo essa ponte me separa, como escritor, do conto como coisa escrita, a ponto de a narrativa ficar sempre, após a última palavra, na outra margem”. (CORTÁZAR, 1974, p. 230)

Surge, então, a linguagem estabelecendo pontes discursivas, delimitando margens, criando contos, fantaseando o duplo, vivenciando personagens literários e corpóreos, indo sobre a ponte a partir de um ser de palavras/linguagens, para um ser textual. Indo para o texto, o duplo.

O duplo é figura central de nossas reflexões, seja como elemento provocador de impotência (segundo o já desenvolvido na vivência -rankiana- assustadora diante do duplo), seja como causa de insegurança diante à castração freudiana (percebida pelo ser e o texto), todas estas temáticas estando extremamente presentes nos estudos literários, como se pode apreciar ao longo das nossas observações, mas também nas abordagens psicanalíticas tanto rankianas, freudianas, quanto lacanianas: análises psico-literárias sempre numa tentativa de descrição da formação do ser, e que para a nossa análise se tornam bases-justificativas e ponto de partida para a compreensão da construção textual, da passagem/construção (textual) de um texto (o original) para o seu duplo (o traduzido). Analogia 'ser-texto' singular a ser abordada e ilustrada nos capítulos seguintes e que nos abrirá as portas para esse jogo de amarelinha, onde a primeira pedra será jogada a partir do texto de partida, para vivenciar a tensão criativa, esse coágulo cortazariano, essa angústia na passagem, essa mimese, essa identificaşão e repulsa paradoxais diante do outro -o duplo- na procura e na tentativa de atingir o Céu: o texto traduzido.

De um conto [de uma traducão] assim se sai como de um ato de amor, esgotado e fora do mundo circundante, ao qual se volta pouco a pouco com um olhar de surpresa, de lento reconhecimento, muitas vezes de alívio e tantas outras de resignação. O homem que escreveu [que traduziu esse conto [essa traducão] passou por uma experiência ainda mais extenuante, porque de sua capacidade de transvasar a obsessão dependia o regresso a condições mais toleráveis; e a tensão do conto [da tradução] nasceu dessa eliminação fulgurante de idéias intermédias, de etapas preparatórias, de toda uma retórica literária deliberada, uma vez que estava em jogo uma operação de algum modo fatal que não tolerava perda de tempo. [...] (CORTÁZAR, 1974, p. 231, Grifos meus).

Os contos cortazarianos apresentam influências de outros autores (Edgar Alan Poe, Lautréamont.) que abordaram a narrativa com a figura do duplo. Porém, no 
conto Lejana, (CORTÁZAR, 1951), e segundo as palavras de Cortázar, as marcas de intertextualidade não se evidenciam: "No creo que se trate de una influencia literaria. Cuando yo escribí ese cuento [...], Lejana, entre 1947 y 1950, [...] esa noción de doble no era [...] una contaminación literaria. Era una vivencia." (BERNECHEA, 2012, p. 23).

No conto Lejana, uma das personagens, Alina Reyes, la pituca ou grã-fina de Buenos Aires, vislumbra-se em um outro país distante, a Hungria, como uma mulher diferente, numa outra situação econômica: ao invés da rica que é, vê-se mendiga. Assim, toda vez que Alina percebe, como num sonho, a presença da sua 'outra', do seu duplo, percebe uma mulher pobre e maltratada, padecendo frio, em Budapeste. No conto, a personagem transforma-se na mendiga e a mendiga se torna a 'rainha'. Tudo se funde no frio e na neve. Os sapatos furados, o vestido cinza. Lindíssima. Segundo o próprio Cortázar:

[...] la mendiga sale del cuerpo del cuerpo maravillosamente vestido da la pituca, mientras que la rica fina se queda en el puente transformada en mendiga [...] se trata de una pituca de Buenos Aires que tiene, por momentos, una especie de visión Ella no está sólo en Buenos Aires, sino también en otro país muy lejano donde todo es opuesto: allí, es mujer y pobre, una mendiga. Poco a poco, la mujer imagina quién podría ser la otra mujer, hasta que va a buscarla y la encuentra en un puente y se abrazan. Y se produce el cambio dentro del doble. La mendiga parte con el cuerpo maravilloso cubierto de pieles e la pituca se queda en el puente como una mendiga andrajosa [...] (CORTÁZAR, 1951, p. 36).

A personagem Alina Reyes coloca o problema do desafio ao destino, à luta entre ela 'rainha' e a mendiga abatida pelo frio, numa ponte de Budapeste. Escrito a partir de dois pontos de vista narrativos diversos -em forma de diário e em seguida a partir de um narrador onipresente- o conto joga com a ambivalência de desejo de proteção e auto piedade.

Como em outros contos, há a presença alegórica da ponte. Em Rayuela (CORTÁZAR, 1963), por exemplo, enquanto o personagem Horácio observa o rio a partir de uma ponte, a personagem Maga o adverte de que se afogará em 'rios metafísicos'. Em Lejana depara-se o leitor com uma outra ponte, desta vez sobre o Danúbio, um rio gelado, envolto em vento, onde a mendiga espera a rainha, o seu duplo. A própria personagem, Alina vê-se forçada a definir o seu direito à existência, entre duas 'orillas': se existe como alguém que vai ao concerto ouvir Chopin, ou se é mendiga maltratada em Budapeste, congelada pelo vento do rio.

Alina Reyes odeia e ama ao mesmo tempo. Sentimentos alternados de culpa e castigo, prazer e aflição, no sofrimento da mendiga na ponte, e na rotina sonâmbula do seu mundo aristocrático noturno. $O$ ódio vem sempre à noite e se tece de anagramas e pontes lançadas para Budapeste, a partir de Buenos Aires: Tengo que repetir versos, o el sistema de buscar palabras con $a$, después con $a$ y $e$, con las cinco vocales, con cuatro [...] Así paso las horas: de cuatro, de tres y dos, y después palíndromos... (CORTÁZAR, 1951, p. 29)

Mas o encontro tão fantasiado, aquela fusão dos seres assegura a vitória:

Y las dos se abrazaron rígidas y calladas en el puente. (CORTÁZAR, 1951, p. 39) 
[...]

Ceñía a la mujer delgadísima, sintiéndola entera y absoluta dentro de su abrazo, con un crecer de felicidad igual a un himno, a un soltarse de palomas, al tío cantando. Cerró los ojos en la fusión total, reuyendo las sensaciones de afuera, la luz crepuscular, repentinamente tan cansada, pero segura de su victoria, sin celebrarlo por tan suyo y por fin. (CORTÁZAR, 1951, p. 39).

A Alina rica funde-se na outra, a fusão do duplo se concretiza. A mendiga pobre entra no corpo da burguesa, metamorfoseando-se nela, parte ricamente vestida sem olhar para trás. A Alina nova, sem os seus sapatos furados, mas na vitória: 'ia lindíssima em seu vestido cinza, um pouco de cabelo solto contra o vento, sem voltar o rosto e seguindo'. Da ponte para a praça.

No duplo registro desse conto, a personagem é dotada da consciência do Outro. Os mesmos pés, que sentem o gelo do Danúbio, sentem a neve nos sapatos nas festas de Buenos Aires, ou no salão dos concertos, onde se ouve Chopin. Não se trata restritivamente de um sonho, mas da vigília da insônia, da vigilância objetiva das coisas. Essa certeza ou essa consciência da realidade impõe a vitória da ilusão, sobre a reconciliação ou a fusão dos seres. Essa presença é momentânea, mas constante na narrativa cronológica do diário de Alina. A cena da ponte define e resolve um problema existencial, pondo ao alcance do indivíduo sua possibilidade de continuar vivendo em meio a anagramas e combinações e, simultaneamente, seguir vivendo na fusão com o duplo.

A maneira de conclusão, poder-se-ia afirmar que a literatura do fantástico consegue manter o leitor aberto a esse limiar de percepção, onde imaginário e real se confundem. Percebe-se, com bastante razão, que o conto fantástico não produz uma ficção codificada enquanto tal, fechada dentro de seu próprio registro, mas extrapola as convenções ficcionais ao apresentar a ótica do personagem não como puro delírio, mas como o real possível.

O propósito destas reflexões, ao investigar a produção cortazariana de contos fantásticos, foi tentar descrever as inquietações de Julio Cortázar, mas também as de todo escritor, a partir da ótica psicanalítica e literária de Otto Rank e de Freud. Tendo esse objetivo como premissa de base e ponto de partida, ilustrou-se a partir de Julio Cortázar quem exprime suas procuras e obsessões literárias movimentados pela figura do duplo. Um duplo que se torna vivência, perseguição, sonho, fantasma, presença dupla do sentimento bipolar de amor e ódio. O narrador (para o interesse desta pesquisa, o narrador cortazariano) aborda a questão do duplo impondo compromisso e criação ao seu leitor, impondo duplicidade. Cortázar se declara habitado pelo imaginário e cria pontes lingüísticas e sentimentais com o seu leitor, se passeando ambos dois num universo de palavras na procura do céu, do outro lado, da outra margem, do outro, de uma outra traduzibilidade.

Assim sendo, o intuito deste trabalho foi mostrar que a produção literária estabelece pontes tradutórias: do narrador para o seu leitor, do autor para o seu tradutor, de Um para um Outro; do texto fonte para o texto traduzido (e vice-versa).

Nesse trânsito de duplicações ou réplicas, instaura-se assim, um ponto de partida que nos permitiu desenvolver as figuras da analogia, do original-cópia, tópicos fundamentais nas nossas reflexões, sendo a ponte que esta dissertação 
estabeleceu aquela que poderia ter sido colocada por Freud ao afirmar que, no texto $O$ Estranho, há uma duplicação, divisão e intercâmbio do eu (selff) e ele se substitui por um estranho. Em outras palavras, há uma duplicação, divisão e intercâmbio do eu $($ self). E, finalmente, há o retorno constante da mesma coisa. Essas reflexões freudianas nos permitem introduzir também o conceito do tradutor como o duplo do autor. Portanto, esta investigação pretendeu dar provas da complexidade de todo processo de tradução nas suas múltiplas acepções, e também pretendeu oferecer um novo olhar do ato tradutório, estabelecendo uma analogia entre a criação do ser e a formação textual, onde as lutas para atingir o alvo caracterizam-se pela presença de elementos extremos e em pugna: briga de amor é ódio entre o texto de base e texto traduzido; violência e fragmentação para chegar à formação do ser-sujeito e do texto; presença incansável e polêmica do duplo. Unheimlich.

Ao colocar o conceito do tradutor como duplo do autor (e o do texto traduzido como o duplo do texto fonte), a premissa desta pesquisa tenta se debruçar sobre as velhas e tradicionais percepções e vivências do tradutor, do traduzido, quem como já fora desenvolvido, carrega infatigável a sombra da inferioridade, da duplicidade desprestigiada, mas a nossa tentativa é feita a partir de uma visão nova. $\mathrm{O}$ intuito nosso, é aquele de introduzir uma outra leitura-tradução, é dar nova luz, tentando analisar o duplo -o outro- como presença, como um Outro necessário, possível e estranho - unheimlich-; um duplo (outro) fundamental, sem o qual, o texto não atinge o estatuo textual, e para a nossa analogia texto-ser, sem o qual, o ser não atinge a condição de ser-sujeito.

Por conseguinte, poder-se-ia concluir que, Julio Cortázar, assim como também todos os cronópios criadores de pontes e de duplos, procuram o céu textual na obsessão terrível e maravilhosa do tecido narrativo: indo do lado de cá para o lado de lá das palavras, das línguas e linguagens. Cortázar traduz e se traduz na silenciosa e escandalosa felicidade infernal, à procura daquele outro -texto e ser- que lhe premitirá amar e odiar, se tornar Axolotl, Alina rica indo da ponte para a praça, atingir o céu de gesso e o Céu do Outro; se tornar texto.

\section{REFERÊNCIAS}

Cortázar, J. Carta a Roberto Fernández Retamar. 10 de mayo 1967. Publicada: El Periodista, año 1, n• 31, abril 1985. IN: 16 cuentos latino-americanos, 1992.

Carvalho, E. Anotaçoes sobre o mapa de Julio Cortázar. 1998. https://constelar.com.br/revista/edicao67/cortazar1.htm

Cortázar, J. Valise do cronópio. São Paulo: Editora: Perspectiva Debates. Tradução: Davi Arrigucci Jr. e João Alexandre, 1974.

Cortázar, J. Contos: (http://www.ciudadseva.com/textos/teoria/opin/cortaz4.html

Cortázar, J. Rayuela. Buenos Aires: Editorial Sudamericana, 1963.

Cortázar, J. La fascinación de las palabras. Charla con Omar Prego, 1998. http://www.cortazartextual.com.ar/salida.html. Los cuentos: un juego mágico.

Freud, S. (O Estranho ("Das Unheimliche". In: Obras Psicológicas Completas. -1969(Volume XVII -1917-1919-) 
González Bermejo, E. (1994) Revelaciones de un cronopio. Conversaciones con Cortázar. https://ciudadseva.com/texto/conversaciones-con-cortazar/

Hans Heinz Eweres, H. (1913). Film: O estudante de Praga

Hoffman, E. T. A. (1969). "O Homem de Areia" em Contos Fantáticos. Ímago, Rio de Janeiro.

Marta Álvarez, Antonio Jesús Gil González, Marco Kunz (2012). Metanarrativas bispánicas. Latin American fiction. Ed. Alfredo Barnechea. Lima, Alfaguara http://www.herbogeminis.com/IMG/pdf/CORTAZAR.pdf

Rank, O. (2013). O duplo: um estudo psicanalítico. (E.L: Schultz, trad.) Porto Alegre: Dublinense 